\title{
Possible Effect of COVID-19 Vaccines on Menstruation in Cape Coast, Ghana, West Africa: Case Series Report
}

\author{
Diallo Abdoul Azize1*, Ekanem Evans², Pinkrah Richard² \\ ${ }^{1}$ Department, of Obstetrics and Gynaecology, School of Medical Sciences, College of Health and Allied Sciences, University of \\ Cape Coast, Cape Coast, Ghana \\ ${ }^{2}$ University Health Services, University of Cape Coast, Cape Coast, Ghana \\ Email: *diallo.azize@uccsms.edu.gh
}

How to cite this paper: Azize, D.A., Evans, E. and Richard, P. (2021) Possible Effect of COVID-19 Vaccines on Menstruation in Cape Coast, Ghana, West Africa: Case Series Report. Open Journal of Obstetrics and Gynecology, 11, 1650-1656.

https://doi.org/10.4236/ojog.2021.1111154

Received: October 1, 2021

Accepted: November 27, 2021

Published: November 30, 2021

Copyright $\odot 2021$ by author(s) and Scientific Research Publishing Inc. This work is licensed under the Creative Commons Attribution International License (CC BY 4.0).

http://creativecommons.org/licenses/by/4.0/

(c) (i) Open Access

\begin{abstract}
Covid-19 was declared a global pandemic by the World Health Organization; it has caused more than 4,697,099 deaths worldwide. Since the discovery of Vaccines, the rate of infections and deaths are declining in countries that were able to conduct mass vaccination, making the vaccines the most effect tool in the fight against Covid-19. However, there is still vaccination skepticism. The side effects of vaccines could fuel more skepticism. There are emerging possible new side effects such as abnormal uterine bleeding post Covid-19 vaccination, for which health care providers and the population should be aware. In this paper, we are reporting three (3) cases of abnormal uterine bleeding which seems to be linked to Covid-19 vaccines. We reported two incidents of heavy menstrual bleeding and one incident of inter-menstrual bleeding which are likely associated with COVID 19 vaccination, even though the causality could not be confirmed. Also both types of vaccines, Messenger RNA and Adenovirus vector could possibly be associated with abnormal uterine bleeding. As research is still ongoing, more knowledge would be available, meanwhile, healthcare providers and the population should be made aware of the new possible side effects of Covid-19 vaccines.
\end{abstract}

\section{Keywords}

Covid-19 Vaccines, Abnormal Uterine Bleeding, Abnormal Menstruation, Cape Coast

\section{Introduction}

Since the Covid-19 outbreak in December 2019 in Wuhan, it has infected more than $228,807,631$ people worldwide and caused 4,697,099 deaths [1]. The 
COVID-19 affects all segments of the population and is particularly detrimental to members of those social groups in the most vulnerable situations [2]. The Covid-19 pandemic has affected the way people live interpersonal relationships. In the face of global challenges posed by the COVID-19, scientists worldwide had joined hands to develop Covid-19 vaccines to save life and livelihood and stop the spread of the disease.

The effort to find vaccines was successful, leading to their discoveries. There are several Covid-19 vaccines currently in use. The first mass vaccination programme in the world started in early December 2020. At least 13 different vaccines (across 4 platforms) have been administered. The Pfizer/BioNtech Comirnaty vaccine was listed for WHO Emergency Use Listing (EUL) on 31 December 2020. The SII/Covishield and AstraZeneca/AZD1222 vaccines (developed by AstraZeneca/Oxford and manufactured by the State Institute of India and SK Bio respectively) were given EUL on 16 February [3].

In Ghana, the mass vaccination programme began in March 2021 and more than 405,971 people are currently fully vaccinated [4].

There are known side effects of the vaccine reported by the manufacturers, which include:

- having a painful, heavy feeling and tenderness in the arm where you had your injection;

- headache or muscle ache;

- joint pain, feeling tired;

- chills, fever (temperature above $37.8^{\circ} \mathrm{C}$ );

- nausea or vomiting;

- Cerebral vein thrombosis [5].

There are emerging possible new side effects such as abnormal uterine bleeding post Covid-19 vaccination. In this paper, we are reporting three (3) cases of abnormal uterine bleeding in a context of abnormal menstruation, which symptoms seem to be linked to Covid-19 vaccines.

\section{Patients and Methods}

\subsection{Study Design}

A retrospective observational case-series analysis was performed to record the circumstances, the date of vaccinations, the onset of incidents and the outcomes.

\subsection{Patients}

The three participants are regular attendant at the Gynecology clinic of the STADIUM CLINIC located in the Cape Coast metropolis in Ghana for various raisons. They reported for their follow up appointments and reported the incidents following the Covid-19 vaccination.

\subsection{Data Collection}

Data were collected via thorough clinical history taking and using the vaccina- 
tion card to confirm the date of vaccination and to relate the incidents to the vaccines.

\section{Cases}

\subsection{Case 1}

A 41-year-old P0 without any known past medical or surgical history, being manage for sub fertility due to male factor. She has a 28 days regular menstrual cycle and menstruates for 4 days, changes 2 pads each day. Her LMP was on the $15^{\text {th }}$ August, 2021 and she was expecting her next menses on $12^{\text {th }}$ September, 2021. She received the $2^{\text {nd }}$ Dose of ASTRA ZENECA VACCINE on the $8^{\text {th }}$ September, 2021, and the next days she experienced vaginal bleeding which she believed was not her usual menstruation. The bleeding continued with her menses and lasted for eight days. She did not report immediately to any health facility for assessment and care. She was seen at the clinic 2 weeks after for the follow up with regards to the subfertility, and it was at that visit, she reported the incident which happened after the Covid19 vaccination (Figure 1).

\subsection{Case 2}

A 33-year-old $\mathrm{P}^{\mathrm{a}}{ }^{\mathrm{a}}$ without any known past medical or surgical history, being managed for severe dysmenorrhea secondary to endometriosis. She has Levonorgestrel IUCD in situ. She has a 28 days regular menstrual cycle and menstruates for 3 days, changes 2 pads each day since the insertion of the IUCD. She travelled to USA in May 2021 for a family visit, where she received the $1^{\text {st }}$ Dose of BioNtech/Pfizer vaccine during the last day of her menses, which prolonged for more than 30 days. In the course of the abnormal menstruation, she received the $2^{\text {nd }}$ dose of the vaccine. She was put on tablet Tranexamic acid $500 \mathrm{mg}$ TDS + Iron supplement daily. She returned to Ghana a couple of weeks after and reported to her gynecologist for follow up and she disclosed the incident (Figure 2).

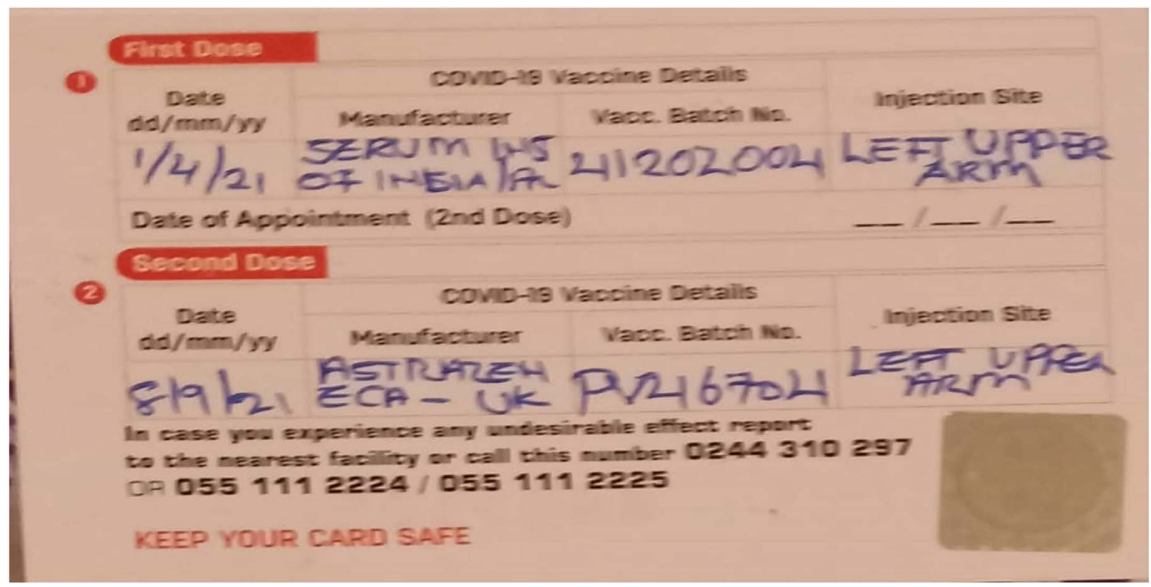

Figure 1. Picture showing the Case 1's vaccination records, indicating the dates she received vaccines. 


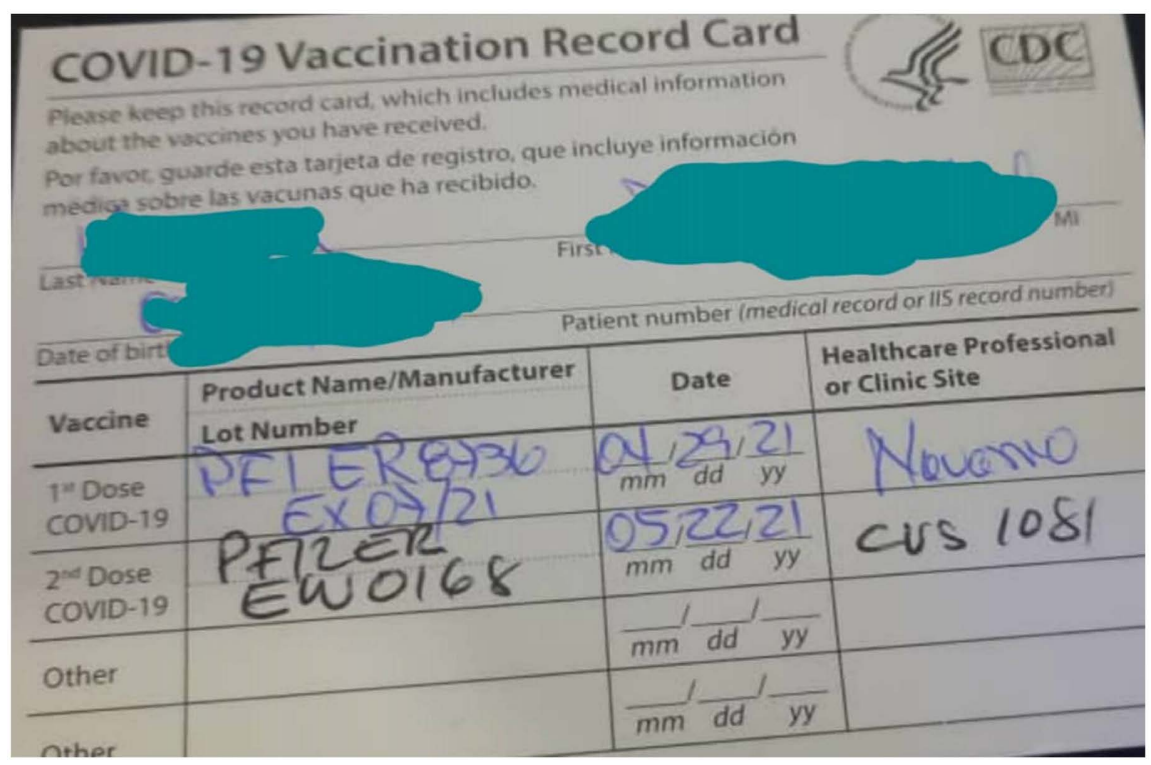

Figure 2. Picture showing the Case 2's vaccination records, indicating the dates she received vaccines.

\subsection{Case 3}

A 34-year-old P3 ${ }^{\text {aa }}$ without any known past medical or surgical history, know to have uterine leiomyoma which was discovered 2 years ago during her last pregnancy. She is asymptomatic of the uterine leiomyoma. She has a 24 days regular menstrual cycle and menstruates for 5 days, changes 2 pads each day. She received the $2^{\text {nd }}$ Dose of ASTRA ZENECA vaccine on $2^{\text {nd }}$ September 2021, four days after the onset of the menses (on the last day of her menses). This current menses lasted for 9 days and was associated with small clots. She says she has never had a similar menstrual pattern. She reported for assessment after her menses has ended, and an ultrasound scan confirmed the presence of intramural leiomyomas without mass effect on the endometrium. The heavy menstrual bleeding was attributed initially to the leiomyomas, however her subsequent menses returned to the normal five days duration without any associated clots. There could be a possible link between the menorrhagia and the Covid-19 vaccine (Figure 3).

The socio-demographic characteristics of the participant are summarized in Table 1.

Limitation: Our cases reported to us for assessment after the incidents have clinically resolved, which did not allow us to conduct full assessment and investigations to rule out other possible causes of abnormal menstruation. However, our $2^{\text {nd }}$ and third cases have returned to their previous menstrual patterns in the following cycles, which could possibly exclude other causes than the Covid-19 vaccination.

\section{Discussion}

In our cases reviewed we found 2 incidents of heavy menstrual bleeding and 1 
Table 1. Socio-demographic features of the participants.

\begin{tabular}{ccccccc}
\hline & AGE (YEARS) & SEX & RACE & $\begin{array}{c}\text { MARITAL } \\
\text { STATUS }\end{array}$ & $\begin{array}{c}\text { EDUCATIONAL } \\
\text { LEVEL }\end{array}$ & PROFESSION \\
\hline CASE1 & 41 & F & African (Black) & Married & Tertiary & Administrator \\
CASE2 & 33 & F & African (Black) & Married & Tertiary & Fashion designer \\
CASE3 & 34 & F & African (Black) & Married & Tertiary & Health worker \\
\hline
\end{tabular}

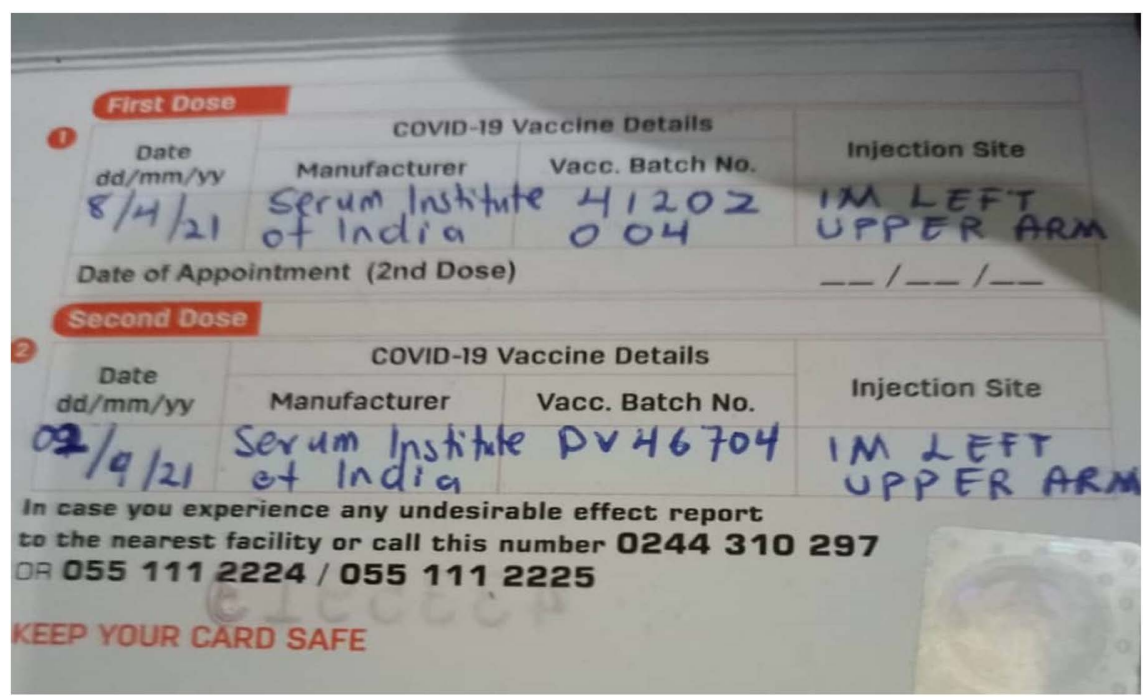

Figure 3. Picture showing the Case 3's vaccination records, indicating the dates she received vaccines.

episode of inter-menstrual bleeding which are likely associated with COVID 19 vaccination, even though the causality cannot be confirmed.

Also both type of vaccines, Messenger RNA and Adenovirus vector could possibly be associated with abnormal uterine bleeding.

We are reporting theses cases because there is no available data in literature on post Covid-19 vaccines menstrual abnormalities reported in black population and particularly in Sub Saharan Africa.

However there is a growing concern in UK and United state of America about the link between abnormalities in menstruation and COVID 19.

In UK, Some women have reported temporary changes in their periods after receiving the Coronavirus vaccine. Some women have reported heavier bleeding than usual, delayed periods or unexpected vaginal bleeding [6].

Current evidence suggests there is no link between period problems or unexpected vaginal bleeding and COVID-19 vaccines [6]. However the Medicines and Healthcare products Regulatory Agency (MHRA) and other experts are closely monitoring and evaluating these reports. Longer term follow-up is ongoing in the UK and elsewhere to better understand this reaction [6].

As it stands now, there is no available theory of pathophysiology to link the Covid-19 vaccine and menstrual irregularities, more research and data are needed. 
Recently in September 2021, Johns Hopkins Medicine's Department of Gynecology and Obstetrics is one of five institutions selected by the National Institutes of Health (NIH) to conduct research to explore the potential impacts of COVID-19 vaccination on menstruation [7].

This research will help us better understand if there is a real link between the COVID-19 vaccines and these menstrual changes, or if it is something else, such as lifestyle changes or pandemic-related stress [7].

Lessons learnt from our cases:

As many African and Asian countries are embarking of mass vaccination against COVID-19, health care professional should be aware of the occurrence of menstrual irregularities after the vaccination and they should report those cases to the drugs regulatory agencies.

And women receiving the vaccines should be counseled to report any occurrence of menstrual irregularity and they should be provided with medical care.

\section{Conclusions}

We reported two incidents of heavy menstrual bleeding and one incident of inter-menstrual bleeding which are likely associated with COVID 19 vaccination, even though the causality cannot be confirmed. Also both types of vaccines, Messenger RNA and Adenovirus vector could possibly be associated with abnormal uterine bleeding.

As research is still ongoing, more scientific knowledge would be available, meanwhile, healthcare providers and the population should be made aware of the new possible side effects of Covid-19 vaccines.

\section{Conflicts of Interest}

The authors declare no conflicts of interest regarding the publication of this paper.

\section{References}

[1] Coronavirus Disease (COVID_19) Pandemic. https://www.who.int/emergencies/diseases/novel-coronavirus-2019

[2] Everyone Included: Social Impact of COVID-19. https://www.un.org/development/desa/dspd/everyone-included-covid-19.html

[3] Coronavirus Disease (COVID-19): Vaccines. https://www.who.int/news-room/q-a-detail/coronavirus-disease-(covid-19)-vaccine $\underline{\mathrm{S}}$

[4] Vaccination Updates. https://ghanahealthservice.org/covid19/

[5] Side Effects of the Coronavirus Vaccines. https://www.nhsinform.scot/covid-19-vaccine/the-vaccines/side-effects-of-the-coro navirus-vaccines

[6] Hunter, P.R. (2021) Thrombosis after covid-19 vaccination. BMJ, 373, n958 https://doi.org/10.1136/bmj.n958

[7] COVID-19 NEWS: Study to Investigate Impacts of COVID Vaccines on Menstrua- 
tion.

https://www.hopkinsmedicine.org/news/newsroom/news-releases/covid-19-news-st udy-to-investigate-impacts-of-covid-vaccines-on-menstruation 